\title{
Substrate composition and adult distribution determine recruitment patterns in a Caribbean brooding coral
}

\author{
M. J. A. Vermeij ${ }^{*}$ \\ Cooperative Institute for Marine and Atmospheric Studies (RSMAS/UM), NOAA Fisheries, \\ Southeast Science Center, 75 Virginia Beach Drive, Miami, Florida 33149, USA
}

\begin{abstract}
This study demonstrates the interactive effect of both substrate composition and adult presence on recruitment and mortality patterns of the earliest life stages in the coral Siderastrea radians in the Florida Keys. Low substrate complexity on a wreck (the 'Benwood') facilitated the location and identification of recently settled coral recruits $\left(<1 \mathrm{~mm}^{2}\right)$. Increased adult cover and changes in substrate composition (mainly the presence of crustose coralline algae) enhanced local recruitment, indicating that positive changes in substrate composition acted as an important factor enhancing coral recruitment. Spatial differences in the number of arriving recruits dictated future patterns in local population density as mortality probabilities did not vary spatially. S. radians populations showed the potential to be regulated in a density-dependent manner as suitable settlement substrate was, or could become, limited by (1) its natural availability or (2) preemption by growing adults. Adult removal resulted in a $46 \%$ decrease in local $\left(<1 \mathrm{~m}^{2}\right)$ recruitment, indicating that $S$. radians populations were facultatively closed at this spatial scale. Therefore, the $S$. radians/Benwood system allows for a detailed description of the processes that create structure in coral populations. Defining the relative contribution of processes that are important in shaping coral population structure contrasts with the more common approach in which only the pattern that results from them is quantified. A processbased approach will allow for a more rigorous investigation of coral population dynamics with obvious benefits for coral reef science and conservation.
\end{abstract}

KEY WORDS: Siderastrea radians - Florida Keys · Recruitment - Mortality · Regulation · Density dependence

Resale or republication not permitted without written consent of the publisher

\section{INTRODUCTION}

The earliest stages of substrate colonization represent a crucial phase in the development of coral populations. The addition of new individuals to a population has implications for its genetic structure, survival and the composition of the local community. When coral larvae (planulae) start their benthic life-phase, their behavior and survival depends on a variety of environmental factors (e.g. Morse et al. 1988, Lasker \& Kim 1996, Mundy \& Babcock 1998, Harii \& Kayanne 2003). Besides environmental factors, recruitment success and pattern depend on a planula's behavior (Butman 1987, Isomura \& Nishihira 2001, Miller \& Mundy 2003) and the presence of adult colonies (Polachek \& Stimson 1994, Fearon \& Cameron 1997).

Although recruitment dynamics are now well studied for various marine invertebrates (especially those in rocky intertidal zones, e.g. Roughgarden et al. 1985, Connell 1985, Menge 1991), and also temperate sponges (Uriz et al. 1998), this existing knowledge has hardly been used in the study of coral population dynamics. Due to large differences in the life history of the organisms involved and differences in environmental setting, the usefulness of studies based on mostly temperate invertebrates as an aid to coral population dynamics can indeed be questioned. The usefulness of a theoretical framework to study the importance of recruitment variation in coral population dynamics seems however undisputed, which makes its scarcity (or absence) a remarkable phenomenon.

A major hindrance to study recently settled coral larvae in the field is their small size and preference for cryptic microhabitats. Secondly, initial settlement patterns become rapidly confounded by post-settlement mortality as mortality in invertebrates is highest during the first few 
days after settlement (Young \& Chia 1984, Wethey 1986). This makes the role of initial variation in settlement in determining distribution and abundance of visible recruits hard to assess as their density and distribution is likely to vary between the time of settlement and observation. Without post-settlement mortality estimates the importance of initial variation in settlement (i.e. when a larva first attaches to the substrate) to local population structure is almost impossible to determine (Keough \& Downes 1982, Caley et al. 1996). The multitude of factors involved and the logistical difficulties involved in surveying the earliest demersal stages thus severely limit our current understanding of the role of recruitment in structuring coral populations. Both recruitment and the 'juvenile' stage are therefore often operational definitions (Connell 1985), i.e. they are at best crude approximations of the actual phenomena of interest.

To understand recruitment and mortality patterns, it is important to distinguish between factors that limit recruitment and mortality and those that regulate them (Caley et al. 1996). This has important implications for predictions on population size fluctuations through time: in contrast to limitation (or its absence), a regulated population will never go extinct or reach infinity (Hassell 1986, Hixon et al. 2002). Regulation and limitation differ in the presence of at least 1 demographic rate to be density-dependent in the former. Examples of density-dependent processes include the decrease in per capita recruitment rate or increase in per capita mortality rate within increasing density of individuals within the population. Regulation of recruitment thus mainly occurs through internal dynamics of the coral population whereas environmental factors are likely to serve as limiting factors. The relative importance of these regulatory principles operating over longer periods of time is currently not well understood, in contrast to catastrophic mortality events (e.g. bleaching events and disease or predator outbreaks) that limit coral population development over shorter time periods.

The aim of this study is to illustrate the importance of substrate composition and the distribution of adult colonies in determining recruitment of the coral Siderastrea radians in the Florida Keys. S. radians colonies occur in disturbed shallow-water coral communities but can be locally abundant on shipwrecks as well (M. J. A. Vermeij pers. obs.). The abundance of $S$. radians colonies on wreck substrates represents an ideal model system to explore early life history dynamics in corals. The absence of substrate complexity greatly facilitates the observation of the earliest settlement stages, i.e. recently settled planulae and early metamorphosed stages of recruits. Local numerical dominance (Moses et al. 2003) and evidence for short larval dispersal (Duerden 1904, Neves \& da Silveira 2003) suggest that $S$. radians population dynamics could be partially 'closed' (sensu Hixon et al. 2002), i.e. planulae settle predominantly near or within the adult population. Although at larger spatial scales all systems become closed eventually, systems that are closed at a small spatial scale could provide workable areas to study population dynamics as the local density and distribution of recruits is not confounded by immigration of planulae that originated elsewhere.

Siderastrea radians thrives under disturbed conditions (Lewis 1989, Lirman et al. 2002) and is the dominant species on many wrecks in the Florida Keys (M. J. A. Vermeij pers. obs.). Although not a coral reef framework, a wreck habitat where $S$. radians dominates the coral community allows for a first exploration of the principles underlying variation in recruitment rates for corals, such as substrate composition and the presence of adult colonies.

\section{MATERIALS AND METHODS}

Study organism. The coral Siderastrea radians (Pallas 1766) is a dominant shallow water coral that occurs on limestone pavements and ledges throughout the Tropical Atlantic. This gonochoric brooder (Soong 1991) often occurs in dense monospecific communities (up to $90 \%$ cover; Moses et al. 2003) in which adults and recruits co-occur. S. radians is found in environmentally disturbed habitats (e.g. high sedimentation, temperature and salinity fluctuations; Lewis 1989, Lirman et al. 2002, Moses et al. 2003) that are not tolerated by many other scleractinian species. Although $S$. radians can be locally abundant, it is not well known (as for many coral species) which processes affect its spatial distribution. As adult colonies are sedentary, spatial patterns are initially determined by free-swimming planulae released by the adult colonies year round (Soong 1991), which then become confounded through post-settlement mortality. Planulae of $S$. radians are relatively large (maximum length $0.7 \mathrm{~mm}$ ) and have a ring of zooxanthellae at their oral pole, facing away from the substrate after settlement. Both their large size and the characteristic ring of zooxanthellae make $S$. radians planulae easily identifiable.

Study site. The study site was located on a fore-reef in the Florida Keys Natural Marine Sanctuary near Key Largo (Fig. 1) where the wreck of the 'Benwood' has been submerged since 1942 . The deck forms a $110 \times 10 \mathrm{~m}$ (max. length and width) horizontal platform and is overgrown by a thick layer of crustose coralline algae (CCA). The wreck slopes downward from $8 \mathrm{~m}$ at the stern to $15 \mathrm{~m}$ at the bow. The coral community on the wreck is dominated by Siderastrea radians, but Favia fragum, Porites astreoides, and Diploria spp. are also present. Millepora complenata (Milleporidae), Plexaura and Eunicea spp. (Octocorallia) are dominant non-scleractinian species. 


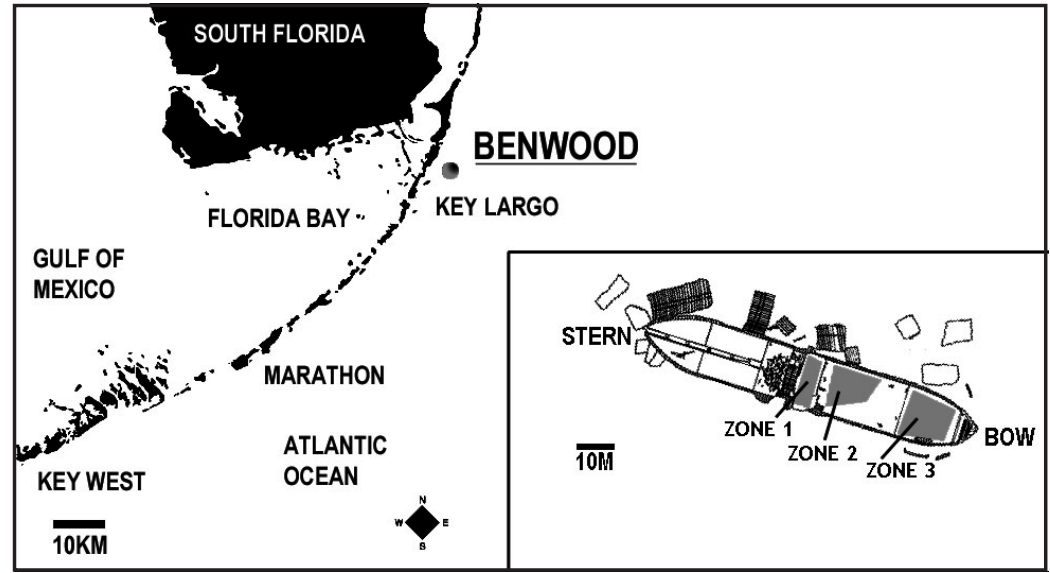

Fig. 1. Location of the 'Benwood' in the Florida Keys reef system. An overview of the wreck is shown on the right with the 3 zones in which this study was carried out shaded in gray

photographed using a Sony P7 Cybershot in an underwater housing (Sony Marinepack $40 \mathrm{~m}$ ). Photos were taken at the highest resolution (3.2 megapixels). A complete series of photographs consisted of 7 successive images taken at 3.0 to 3.5 mo intervals in May 2002, July 2002, November 2002, January 2003, May 2003, August 2003 and December 2003. Colonies on the photographs were traced in Photoshop 7.0 and stored as ${ }^{*}$.bmp files that could be analyzed using image analyses software (Scion Imaging; www.scioncorp.com). Colony size and position were determined. Quantifying the position of new recruits and adult colonies allowed for analyses of spatial patterns in re-

Survey approach. Recruitment and mortality of Siderastrea radians were directly measured by photographic monitoring. Recruitment was defined as the initial sighting of an individual (i.e. a non-mobile, nonmetamorphosed planula or recently metamorphosed, living polyp) on the reef substrate, and included postsettlement losses as more planulae could have arrived and died before being noticed during a survey. Dead recruits were not considered. Adult colonies are defined as every colony larger than $2 \mathrm{~cm}^{2}$, which corresponded to the smallest size of a colony $\left(2.23 \mathrm{~cm}^{2}\right)$ that released planulae in the fecundity experiment (see 'Adult removal and fecundity' below). S. radians populations were monitored in 28 permanent quadrats $(50 \times$ $50 \mathrm{~cm}$ ). The quadrats were stratified into 3 zones of the wreck, spaced $\sim 20$ m apart (Fig. 1), to determine the effects of unforeseen local factors (e.g. hydrodynamic conditions) that could affect recruitment patterns in each zone. Quadrats were randomly positioned within each zone and their position photographed so they could be relocated without installing permanent markers. In order to include a variety of adult densities in the surveys quadrats were sometimes relocated if the density of adult colonies was approximately equal to that of another quadrat. Substrate composition was not considered while placing the quadrats. All quadrats were placed at a depth between 8.5 and $10.7 \mathrm{~m}$.

Photographic monitoring and analysis. The colonies within each quadrat were

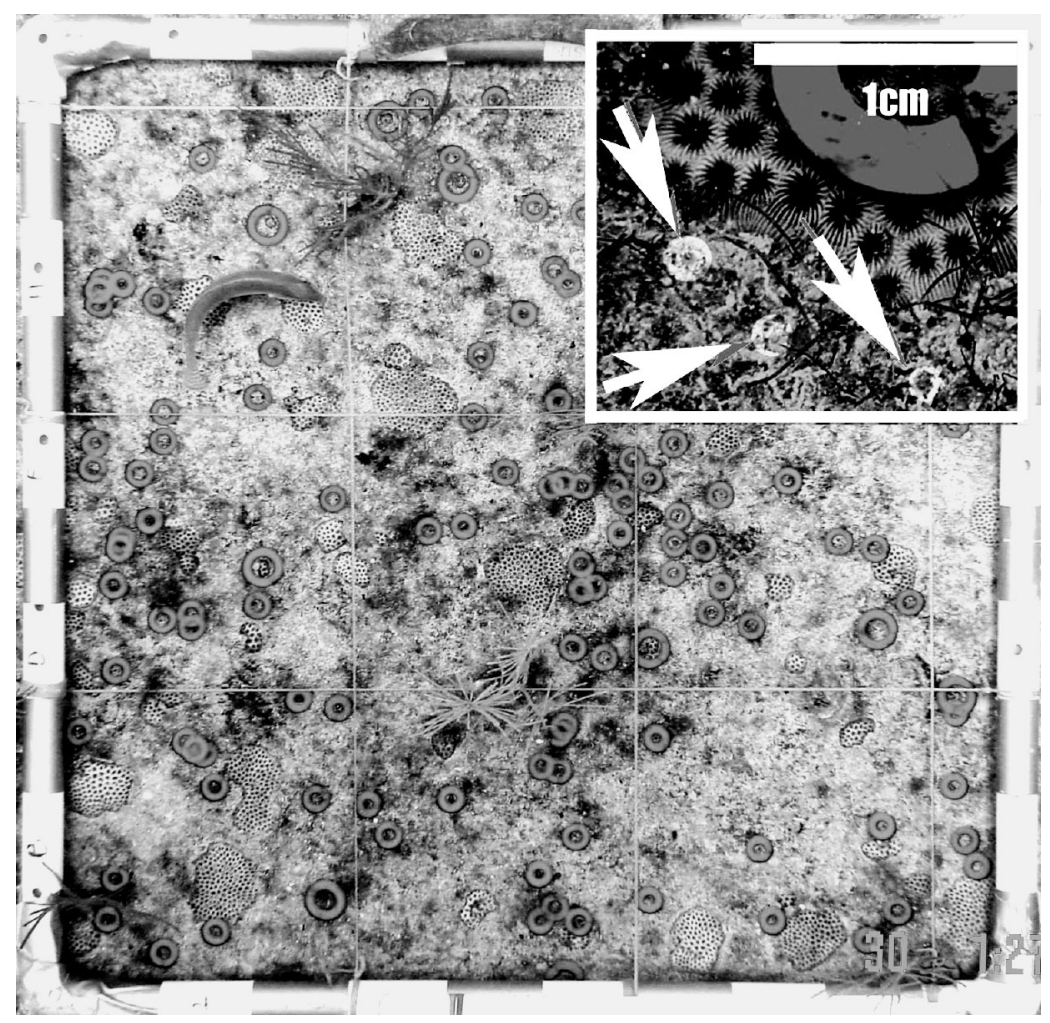

Fig. 2. Siderastrea radians. An example of one quadrat $(50 \times 50 \mathrm{~cm})$ that was sampled in August 2002. Rings indicate the positions of individuals too small to show up on the picture. Different-colored rings (not visible) are used to indicate different sizes of the new settlers. The inset picture shows a detail of 3 recently settled planulae next to an adult colony 
Ring colors and sizes indicated the size of the recruit. All photographs were scaled and linear estimates were always within $0.5 \mathrm{~mm}$ of the true size.

Control of consistency in surveying. At the beginning of the study 6 quadrats were surveyed twice on the same day in random order to determine the likelihood of the observer finding all settlers present. In repeated surveys $99.7 \%$ of the settlers $(n=316)$ were found twice indicating that only few settlers were missed in a survey. During the study, missed individuals were often seen in a successive survey (e.g. at Surveys 1 and 3) so mortality estimates (i.e. for Survey 2) could easily be adjusted. At the beginning of the survey 2730 Siderastrea radians individuals were present within the 28 quadrats and 4123 new recruits were observed during the study. Preliminary inspection of the photos showed that the occurrence of fission and fusion was low, i.e. $0.4 \%(n=2730)$ of the surveyed adult colonies fragmented during the study and asexually produced individuals were not included as recruits.

Substrate composition and calculation of a habitat index. CCA mainly covered the large 2-dimensional deck of the 'Benwood', but other benthic organisms were also present. Percent cover for 9 dominant benthic groups was determined by overlying each quadrate with a Plexiglas sheet marked with 200 random points $(0.1 \mathrm{~cm})$. The substrate type under each point was noted as: CCA, Siderastrea radians colonies already present, encrusting sponges, (erect) turf algae, bare metal, turf algae bound with sand, Millepora spp. and annelids. Preliminary partial least-square analysis (PLS) indicated that CCA, cover by adult $S$. radians colonies, turf algae and bare metal were the most influential variables responsible for overall differences in recruitment $(-0.5>\mathrm{W}>0.5 ; \mathrm{W}=$ weight matrix, see Rannar et al. 1994). CCA and cover by adult $S$. radians colonies scaled positively with recruitment (B [regression coefficient matrix] $=0.21$ and 0.17 , respectively) whereas increased cover by bare metal and turf algae negatively affects recruitment ( $\mathrm{B}=-0.33$ and -0.25 , respectively). For each quadrat substrate quality was then expressed as a quantitative habitat index (Gotelli 1988) in which each of the benthic groups was assigned a score between -1 and +1 , that was then multiplied by their respective abundance ( $\%$ cover). Scores were assigned based on expected differences of various substrate types on recruitment success sensu Gotelli (1988) that were additionally supported by observations on their settlement behavior in controlled experiments (see 'Adult removal and fecundity' below). CCA's induce settlement in many coral species (e.g. Morse et al. 1988, Steneck \& Testa 1997, Heyward \& Negri 1999) and were therefore assumed to have a positive effect on recruitment $(+1)$. Although predation on planulae by adult colonies is generally low in brooding sessile in- vertebrates (Lindquist 1996), adults can limit local recruitment through space preemption (e.g Roughgarden et al. 1985) and therefore a neutral score was (i.e. 0) was assigned to adult coral colonies. When turf algae were present, non-mobile planulae were observed between their branches (M. J. A. Vermeij pers. obs.), indicating a potential mechanism by which algal turfs impeded coral settlement. Settling planulae preferred CCA covered substrates over bare metal surfaces for settlement (see 'Adult removal and fecundity' below). As turf algae hinder settlement and bare substrate was avoided by settling planulae, both were assigned negative scores (-1). Temporal variation in substrate composition was relatively small (M. J. A. Vermeij unpubl. data collected at the same site in 2004) and habitat indices change on average $11.5 \%$ per 3 mo $(\mathrm{SD}=$ $10.0 \% ; n=28$ ). In addition, the relative order of the quadrates based on their habitat index remained identical between successive sampling periods (M. J. A. Vermeij unpubl. data). Substrate composition was determined in July and December 2003 and only used in relation to the recruits arriving between April 2003 and December 2003, the period with highest recruitment.

Recruitment was standardized among successive survey periods to correct for temporal fluctuations in recruitment using the following formula:

$$
S P_{q, t}=\frac{P_{q, t}}{\operatorname{Max} P_{t}}
$$

where $S P=$ standardized recruitment, $P=$ the number of recruits in quadrat $q$ during survey $t, \operatorname{Max} P_{t}=$ the maximum number of recruits recorded in 1 quadrat during survey $t$. These values (i.e. $S P_{q, t}$ ) were then expressed as a function of adult density and the habitat index as a proxy for substrate composition.

Adult removal and fecundity. To determine whether new recruits were produced by nearby $(<50 \mathrm{~cm})$ adults, all adults were removed in 5 additional quadrats in July 2003. Quadrats were placed in the same zone as 10 regular quadrats (Zone 2) that now doubled as controls in the removal experiment. Quadrates were placed such that they contained approximately the same adult density and substrate composition as the control quadrates. Using hammer and chisel all adult colonies were carefully removed leaving the underlying calcareous layer intact. A small chisel $(0.5 \mathrm{~cm})$ was used to remove recruits that were already present. Great care was taken not to damage the substrate composition itself. Quadrats in which the adults were removed were monitored simultaneously with the 28 regular quadrats. Additional surveys of the quadrats in which adults were removed were conducted in March and July 2004 to determine whether the removal of adults consistently lowered the number of recruits in successive sampling periods. 
To obtain an indication of potential planulae production I collected 12 Siderastrea radians colonies from the Benwood in August 2003. Colonies were selected to represent the size ranges present on the 'Benwood'. Colonies were transported in coolers to shaded outdoor flow-through aquaria. Each colony was placed on a small PVC platform $(2 \mathrm{~cm})$ in a 21 tank. Released planulae gathered at the bottom and were counted daily until production stopped after approximately $1 \mathrm{mo}$. Small pieces of CCA and metal were added when planulae started to explore the bottom in order to test my assumption that they prefer natural substrates (i.e. dominated by CCA) for settlement.

Statistical analyses. Recruitment and mortality were defined as the appearance and disappearance of individuals within a quadrat $\left(0.25 \mathrm{~m}^{2}\right)$. After testing the assumptions of normality and equal variances, differences in recruitment were analyzed using repeated measures ANOVA. Differences in substrate composition (indicated by the habitat index) and the density of adult colonies were compared using 1-way ANOVA followed by post-hoc analyses (Tukey HSD). The combined effect of adult density and substrate composition on recruitment and mortality was addressed by linear regression or linear multiple regression depending on the number of causal factors under investigation. Spatial patterns in recruitment and recruit mortality, i.e. as a function of distance to adult colonies, were investigated using product-moment correlation as no knowledge exists to a priori define the expected relationships. In addition, standard regression was used to investigate a possible relationship between (1) the mean size of individuals and density of settlers in a quadrat ('competition-density-effect'; Steen \& Scrosati 2004) and (2) between the survival probability of settlers and their density ('self-thinning rule'; Steen \& Scrosati 2004). Negative associations for both relationships indicate intraspecific competition (e.g. for space or food) among recruits.

\section{RESULTS}

\section{Recruitment}

A total of 4123 individuals recruited in the 28 quadrats from May 2002 to December 2003. Recruitment occurred throughout the year but varied through time and between zones (Fig. 3, Table 1). The majority of recruits (>90\%) settled on dead or living CCA. Highest recruitment was observed in the fall (August to November) and decreased 2-/4-fold over the summer. Substrate composition differed among zones (habitat index; ANOVA, $F_{2,25}=3.86, \mathrm{p}<0.05$ ) with post-hoc tests indicating that Zone 3 (Fig. 1) had significantly lower habitat quality than Zones 1 and 2 (Tukey

Table 1. Repeated-measures ANOVA analysis of the effects of sampling period and location (zone) on recruitment (ind. $0.25 \mathrm{~m}^{-2}$ ), mortality (ind. $0.25 \mathrm{~m}^{-2}$ ) and proportional mortality (fraction of newly settled recruits surviving to next survey). ns = not significant

\begin{tabular}{|c|c|c|c|c|}
\hline & SS & df & $F$ & $\mathrm{p}$ \\
\hline \multicolumn{5}{|c|}{ Recruitment (ind. $0.25 \mathrm{~m}^{-2}$ ) } \\
\hline Intercept & 99047 & 1 & 109.78 & $<0.001$ \\
\hline Sector & 6038 & 2 & 3.35 & $<0.05$ \\
\hline Error & 22556 & 25 & & \\
\hline Time & 10570 & 5 & 14.78 & $<0.001$ \\
\hline Time $\times$ Sector & 2826 & 10 & 1.98 & $<0.05$ \\
\hline Error & 17873 & 125 & & \\
\hline \multicolumn{5}{|c|}{ Juvenile mortality (ind. $0.25 \mathrm{~m}^{-2}$ ) } \\
\hline Intercept & 84186 & 1 & 59.00 & $<0.001$ \\
\hline Sector & 9711 & 2 & 3.40 & $<0.05$ \\
\hline Error & 35675 & 25 & & \\
\hline Time & 9894 & 5 & 4.78 & $<0.001$ \\
\hline Time $\times$ Sector & 19501 & 10 & 4.71 & $<0.001$ \\
\hline Error & 51802 & 125 & & \\
\hline \multicolumn{5}{|c|}{ Juvenile mortality (fraction) } \\
\hline Intercept & 24.56 & 1 & 454.69 & $<0.001$ \\
\hline Sector & 0.17 & 2 & 1.56 & ns \\
\hline Error & 1.35 & 25 & & \\
\hline Time & 1.12 & 5 & 8.67 & $<0.001$ \\
\hline
\end{tabular}


HSD; $\mathrm{p}<0.05)$. Reduced habitat quality corresponded to lower overall recruitment. The presence of adults also differed among zones (ANOVA, $F_{2,25}=7.07, \mathrm{p}<$ 0.01 ) and Zone 1 had significantly higher numbers of adults than Zones 2 and 3 (Tukey HSD; p < 0.02). Cumulative recruitment over the entire study period was highest in Zone 1 (high habitat quality, high adult density) and lowest in Zone 3 (low habitat quality, low adult density), whereas Zone 2 showed intermediate numbers of recruits (high habitat quality, low adult density). Forty-one percent of the variation in recruitment could be attributed to variation in adult cover and substrate composition. Multiple-regression analysis showed that both factors contributed nearly equally in explaining overall recruitment variation (Table 2 ). The near equal contributions of adult cover and substrate composition could be the effect of collinearity, however these factors proved unrelated $\left(r^{2}=0.04 ; p=0.28\right)$. The combined effect of adult cover and substrate composition, indicated by the habitat index, is shown in Fig. 4.

\section{Mortality}

Mortality patterns paralleled recruitment patterns and differed over time periods and between zones (Table 1) with lowest mortality probabilities in zone 3 (Tukey HSD; p < 0.05). Interestingly, if mortality was expressed as the proportion of recruits that died during the next sampling period instead of deaths per surface area, the location effect disappeared and mortality was

Table 2. Siderastrea radians. Standard linear multiple regression analysis of predictors of standardized recruitment $\left(S P_{q, t}\right.$ ind. $\left.0.25 \mathrm{~m}^{-2}\right)$ and mortality (proportion of total recruits that died in the next $3 \mathrm{mo}$ ), adult density (ind. $\left[>2.0 \mathrm{~cm}^{2}\right] 0.25 \mathrm{~m}^{-2}$ ) and substrate composition (indicated by the habitat index). ns $=$ not significant

\begin{tabular}{|lccccccc}
\hline Recruitment & $\mathrm{R}_{2}$ & F-ratio & $\mathrm{p}$ & & & \\
\hline Model & & & & & & \\
Coefficients & $\beta$ & $\mathrm{SE}(\beta)$ & $\mathrm{B}$ & $\mathrm{SE}(\mathrm{B})$ & $t_{(81)}$ & $\mathrm{p}$ \\
\hline Intercept & 0.046 & 0.052 & 0.874 & $\mathrm{~ns}$ & & \\
Habitat index & 0.271 & 0.091 & 0.002 & 0.001 & 2.984 & $<0.01$ \\
Adult density & 0.487 & 0.091 & 0.007 & 0.001 & 5.361 & $<0.001$ \\
Juvenile mortality & $\mathrm{R}_{2}$ & $F-$-ratio & $\mathrm{p}$ & & & \\
\hline Model & 0.031 & 1.261 & $\mathrm{~ns}$ & & & \\
Coefficients & $\beta$ & $\mathrm{SE}(\beta)$ & $\mathrm{B}$ & $\mathrm{SE}(\mathrm{B})$ & $t_{81)}$ & $\mathrm{p}$ \\
\hline Intercept & & & 0.395 & 0.044 & 8.903 & $<0.01$ \\
Habitat index & -0.173 & 0.115 & -0.001 & 0.001 & -1.510 & $\mathrm{~ns}$ \\
Adult density & 0.083 & 0.115 & 0.001 & 0.001 & 0.720 & $\mathrm{~ns}$ \\
\hline
\end{tabular}

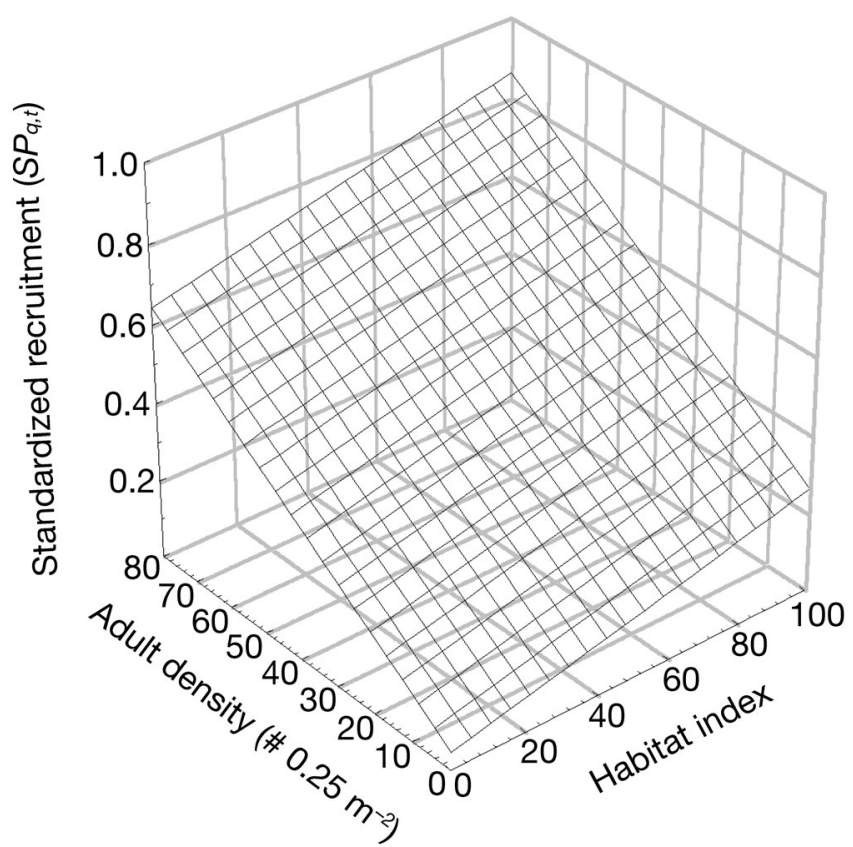

Fig. 4. Siderastrea radians. Effect of substrate composition (expressed as the habitat index; see text for explanation) and adult density (ind. $0.25 \mathrm{~m}^{-2}$ ) on standardized recruitment. To correct for temporal fluctuations, all recruitment was expressed as a relative percentage of the highest recruitment observed within a quadrat during the survey period. A plane was fitted through the data points using a simple, quadratic function

solely dependent on the time of the year (Table 1). Mortality (i.e. the proportion of recruits that died) was significantly higher during the fall (Tukey HSD; p < 0.05 ) and coincided with higher recruitment during these periods.

Absolute mortality, i.e. the number of deaths per $0.25 \mathrm{~m}^{2}$, scaled positively with the number of settlers in the preceding period $\left(\mathrm{r}^{2}=0.74 ; \mathrm{p}<0.001\right)$. The effects of substrate composition and adult density on recruit mortality were therefore investigated using the proportional estimate of recruit mortality (i.e. proportion of recruits that die until the next survey period), which was independent of the total number of recruits present in the quadrat. Variation in proportional mortality could not be related to variation in substrate composition or adult cover (Table 2).

\section{Spatial patterns in mortality}

The probability of recruit survival depended on its position relative to existing Siderastrea radians colonies. The 


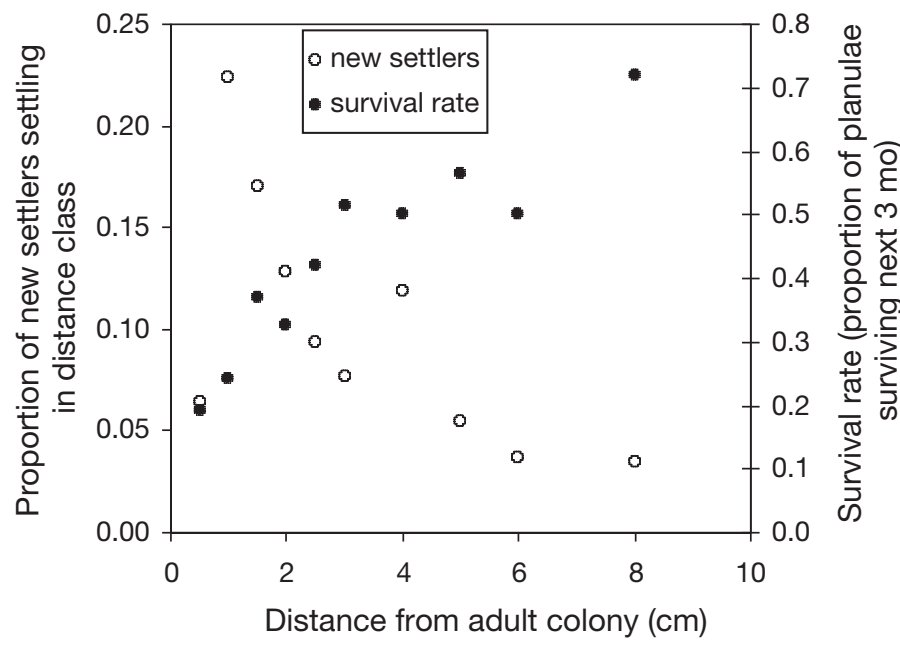

Fig. 5. Siderastrea radians. Proportion of recruits found at different distances from adult colonies (left axis; 0 ) is plotted against their survival probability (right axis; $\bullet$ ) in the same distance classes. The plot was generated using 800 randomly selected recruits from all quadrats and survey periods

likelihood of survival of recruits linearly increased with increasing distance between its position and the nearest adult colony, defined as every colony larger than $2 \mathrm{~cm}^{2}$ (Fig. 5). This contrasted with the initial preference for recruits to occur close to larger colonies (Fig. 5). The interaction of both phenomena, i.e. preference to recruit near adult colonies and higher mortality at these positions, still yielded a higher number of recruits close to adult colonies. Because of parent-centered dispersal patterns, increased survival of recruits (i.e. away from the colony) corresponded to lower densities of recruits (Fig. 5). The negative correlation between the preference of recruits to occur near adult colonies and their successive mortality probability is highly significant $\left(\mathrm{r}^{2}=-0.74 ; \mathrm{p}<0.01\right)$ suggesting that density-dependent survival occurs around adult colonies. Since no information existed on the mechanism underlying this relationship, the term 'distance-dependent survival' is probably more appropriate than 'density-dependent survival'.

No indication was found for a 'competition-densityeffect' (Steen \& Scrosati 2004) where the mean size of individuals would decrease with increasing numbers of settlers $\left(r^{2}<0.01 ; p=0.74\right)$. Secondly, the presence of 'self-thinning rule' (Steen \& Scrosati 2004) was not supported due to the absence of a negative relationship between survival probability of settlers with increasing density of individuals present in the quadrat $\left(\mathrm{r}^{2}=0.11 ; \mathrm{p}=0.11\right)$. This indicates that intraspecific competition among recruits can be ignored as a structuring factor in local Siderastrea radians populations at this spatial scale (Steen \& Scrosati 2004). Inter-
Table 3. Repeated-measures ANOVA analysis of the effects of adult removal (treatment) on recruitment (ind. $0.25 \mathrm{~m}^{-2}$ ) for 4 survey intervals (July 2003-July 2004). ns = not significant

\begin{tabular}{|lrrrc|}
\hline & df & \multicolumn{1}{c}{ MS } & $F$ & $p$ \\
\hline Intercept & 1 & 24850.23 & 89.23 & $<0.001$ \\
Removal & 1 & 1500.63 & 5.39 & $<0.05$ \\
Error & 8 & 278.49 & & \\
Time & 3 & 261.03 & 3.40 & $<0.05$ \\
Time $\times$ Removal & 3 & 142.09 & 1.85 & ns \\
Error & 24 & 76.70 & & \\
\hline
\end{tabular}

estingly, a negative relationship between recruit survival probability and density did exist at the spatial scale of individual colonies (e.g. cm-dm), although the mechanism that causes this relationship needs further research.

\section{Colony removal}

Removing all colonies within a quadrat $(n=5)$ reduced the number of new recruits in the 4 successive sampling periods (Table 3 ). On average the density of recruits decreased by $45.9 \%(\mathrm{SD}=6.3 \% ; \mathrm{n}=5)$ compared to the controls. This illustrated that nearly half of the recruits were produced locally (i.e. by adults within the quadrat), assuming that planulae do not target adult colonies for settlement, which has never been demonstrated for corals, and is contentious for other marine invertebrates (e.g. Uriz et al. 1998, Berntsson et al. 2004). Edge effects likely confounded this observation as recruits might still be 'locally' produced by colonies just outside the quadrat. Hence, the removal experiment provided evidence that at a small spatial scale Siderastrea radians populations could be regarded as a facultatively closed system (sensu Hixon et al. 2002).

\section{Reproduction}

Colony size and planulae production were significantly related $\left(\mathrm{r}^{2}=0.57 ; \mathrm{p}<0.05\right.$; Fig. 6$)$. After leaving the polyp, easily visible planulae $(0.6$ to $0.7 \mathrm{~mm}$ in length) containing zooxanthellae crawled to the edge of the coral colony and onto the substrate. A small fraction $(<10 \%)$ was observed swimming in the water column, whereas the remainder crawled around on the bottom of the aquaria indicating that they probably do not travel far from their release point. Settlement occurred rapidly $(<4 \mathrm{~h})$ as soon as rubble with CCA was placed in the aquaria. Metal chips that were also added were avoided. Within $3 \mathrm{~d}$ after settlement planulae formed a disc-shaped skeleton and started calcification. 


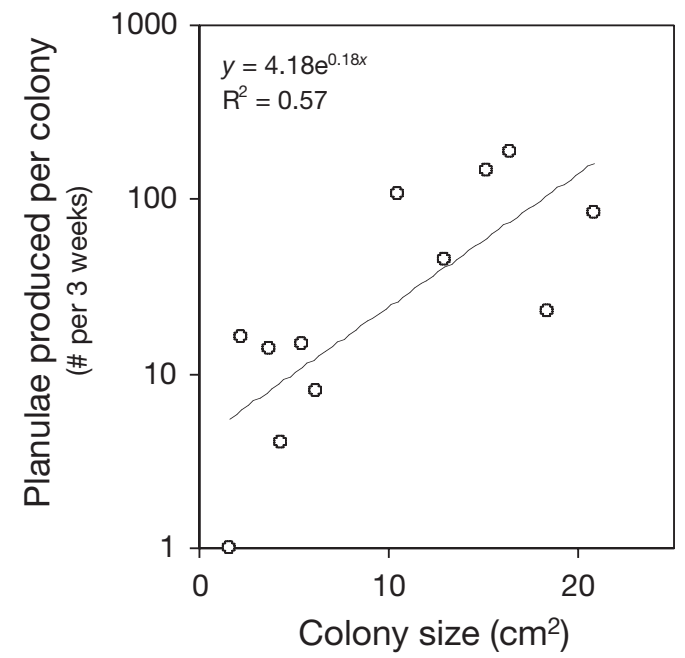

Fig. 6. Siderastrea radians. Planulae production (ind. planulae produced per colony over a $3 \mathrm{wk}$ period; log transformed) as a function of colony size. An exponential function was fitted through the data points

\section{DISCUSSION}

The interactive effects of substrate composition and adult population structure on recruit density and survival of Siderastrea radians were examined over a 2 yr period. Adult colonies produced planulae that settled quickly, causing adult and juvenile populations to overlap. This phenomenon has been observed for other brooding corals (e.g. Sammarco \& Andrews 1988, Carlon \& Olson 1993, Sakai 1997, Dunstan \& Johnson 1998, Hughes et al. 1999, Harii et al. 2002), although brooding per se should not be assumed to imply short dispersal distances of coral offspring (Carlon \& Olson 1993, Harii et al. 2002). The facultative closed nature of $S$. radians populations at small spatial scales $\left(0.25 \mathrm{~m}^{2}\right)$ was shown by the subsequent $46 \%$ decrease in recruitment through time after adult colonies were removed. Low variation in recruitment through space and time provided additional indirect evidence for the closed nature of $S$. radians populations as recruitment typically varies by several orders of magnitude in 'open' populations (Underwood \& Denley 1984, Caley et al. 1996). Active targeting of adults by settling planulae cannot be ruled out as an additional explanation for the reduction in recruitment after adult removal. However, the poor swimming capabilities of $S$. radians planulae, the absence of large variation in recruitment rates in cleared quadrats indicative of 'open' populations (Caley et al. 1996) and the absence of similar behavior in 2 corals with similar life history strategies as $S$. radians (Carlon \& Olsen 1993), favor the hypothesis that planulae are produced by local adult colonies. As $S$. radians has partially self-seeding populations at a small and thus operationally feasible scale, it provides a good opportunity for studies on coral population dynamics, as feed-back mechanisms ensure the effect of local changes in life history elements (e.g. fecundity, growth) on future population composition. Examining interactions between adult population structure, spatial organization and substrate composition on $S$. radians recruitment could serve as a first step to better understand population dynamics of corals in general.

Furthermore, the abundance of recruits depended on substrate composition. The abundance of CCA corresponded to a higher number of recruits, when the adults that produce them are present. The effects of adult cover and habitat quality, i.e. substrate composition, were additive (Fig. 4). This highlights changes in substrate composition, which increase habitat quality (indicated here by the habitat index), as a powerful factor enhancing coral recruitment with obvious implications for reef restoration. CCAs have been shown to be a crucial requirement for settling corals (e.g. Morse et al. 1988, Steneck \& Testa 1996, Heyward \& Negri 1999) and their abundance increases in response to increased herbivory (Steneck \& Dethier 1994) and reduced sedimentation (Steneck \& Testa 1997, Smith et al. 2001). Increasing CCA abundance through alteration of these 2 processes might be a new tool to enhance coral recruitment on degraded reefs, besides traditionally preferred techniques of reseeding (e.g. Rinkevich 1995, Nonaka et al. 2003) or transplantation (e.g. Edwards \& Clark 1998, Lindahl 2003).

Although several studies provided evidence of the importance of active habitat choice by planulae to explain differences in local species distributions (Bak \& Engel 1979, Mundy \& Babcock 1998, 2000), the degree to which pre- and post-settlement processes affect the distribution of individuals within 1 species is currently not well understood (Hunt \& Scheibling 1997). Postsettlement mortality, in terms of the fraction of settlers that will die in the future, was, in contrast to recruitment itself, independent of adult density and substrate composition (Table 1). Therefore, patterns in recruitment basically dictated future patterns in local population density. However, some caution is required. Bak \& Engel (1979) suggested that factors which affect mortality patterns might occur as discrete, periodic events rather than over continuous periods. Potential factors causing catastrophic mortality (e.g. hurricanes, extreme temperatures) did not occur during the study period. Nevertheless, such factors are likely candidates to limit rather than regulate population growth and distributional patterns in Siderastrea radians.

Under normal natural conditions, recruitment had at least the potential to be regulated in a densitydependent manner as suitable settlement habitat was, or could become, limited at a given location by its low natural availability (e.g. Zone 3) or through preemp- 
tion by growing adults. If total growth, i.e. the combined size increase of all individuals present, exceeds losses from mortality, all space will eventually be filled by Siderastrea radians colonies. Although total space occupation was not observed in this study, either due to higher adult mortality or due to the limited period the wreck has been submerged, observations at other locations suggest that the potential for total space occupation by $S$. radians does indeed exist (Moses et al. 2003). Therefore, S. radians populations are, under certain environmental scenarios, regulated and trajectories of population development are predictable.

The distance-dependent survival of newly settled individuals is remarkable as preferred settlement locations are associated with a higher mortality probability (Fig. 5). Thirty years ago an analogous discovery in tropical terrestrial ecology was made independently by Janzen (1970) and Connell (1971), and the relationship has thereafter been referred to as the JanzenConnell hypothesis. Although the generality of this relationship has been questioned for plant species (Hyatt et al. 2003), this paper provides the first indication that parent-centered dispersal patterns and distance-dependent settler survival interact in marine invertebrates. Whether this interaction represents true density-dependence (sensu Hixon et al. 2002) remains unclear as no information exists on the mechanism that would explain the relationship, e.g. competition for optimal microhabitats or increased predation (Harrigan 1972, Lindquist \& Hay 1996). Variation in microhabitat is an unlikely candidate to explain the variability in mortality because the majority of recruits were found on dead or alive CCA. Following Connell (1971), the presence of disease organisms on adult colonies results in the distance-dependency of recruit survival as nearby settlers are more prone to infection than individuals located further away. Pathogens that have sublethal effects on larger (i.e. adult) colonies on which they reside, would have a terminal effect on small settlers. Little information exists on this relationship (but see Polacheck \& Stimson 1994) which deserves further attention as it addresses the effects of diseases on the earliest life stages of corals. However, evidence that diseases are transmitted among nearby colonies (Bruckner et al. 1997) and the fact that colony size and survival probability are positively related (e.g. Bak \& Criens 1981, Hughes \& Jackson 1985, Hughes \& Connell 1987, Babcock 1991, Smith \& Hughes 1999) suggest that the Janzen-Connell hypothesis can play a role in coral population dynamics.

This study suggests that early life history processes, specifically recruitment patterns and subsequent postsettlement mortality are to various degrees dependent on regulatory and limitation mechanisms. Recruitment is limited by habitat availability, but regulated by the number of adults present. At the spatial scale of our study, the potential for a local feedback mechanism exists whereby growth of settled individuals could destabilize future recruitment through space preemption. Because Siderastrea radians life history differs from most other Caribbean coral species, it could be misleading to put the results of this study in a general context. The results of this study are most useful to studies on (coral) species with a life history closely related to that of $S$. radians, i.e. brooding species whose planulae settle within the adult population and that distinguish between habitat types upon settlement. Such species include the Caribbean corals Favia fragum (Lewis 1974, Carlon \& Olson 1993) and Agaricia humilis (van Moorsel 1983), but also non-scleractinian species belonging to the Ascidiacea (Young \& Chia 1984, Olson 1985, Young 1988), Porifera (Uriz et al. 1998) and Alcyonacea (Benayahu \& Loya 1984). Though the findings of this study could be directly applicable for the species mentioned above, the principles could hold for other species at larger spatial scales depending on the median dispersal distance of species planulae. When the scale of dispersal is small, one will be able to observe relationships (through local feedback-effects) between adult population structure, local substrate composition and recruitment patterns within what is traditionally considered a 'study site-scale'. There is no reason to assume that for broadcasting species (e.g. Montastraea, Acropora) similar relationships cannot be discovered, although the logistics of such a study will be extremely difficult. Planulae of the broadcasting Caribbean genera Montastraea and Acropora species show preference for different substrate types upon settlement (M. J. A. Vermeij et al. unpubl. data) suggesting that substrate composition, besides the obvious importance of adults to produce planulae, could be an important factor determining local recruitment. Combining adult population structure, substrate composition and planulae behavior allows for predictions on potential recruitment at a given location that can be compared with observed recruitment in the field. The observed differences could serve as a measure of reef degradation or conservation success.

Progress in formulating generalizations concerning the ecology of reef corals may be hampered by failure to recognize the interaction of substrate composition and species life history characteristics and how this interaction acts across spatial scales. This study aimed to provide a first step in this direction, however, neglecting species-specific attributes could also result in the formulation of generalizations useless to reef conservation efforts and reef science. Combining model-systems (such as the Siderastrea radians/'Benwood' system) with detailed studies on individual species ecological attributes (e.g. life history strategies, 
longevities, habitat preferences) may provide a new route, in addition to the more traditional a posteriori inference based on surveys of entire communities, to understand the role of recruitment in shaping coral communities. Better insight in these patterns and the processes underlying them will be of fundamental importance to reef science and will help to improve existing conservation measures.

Acknowledgements. This work was carried out under permit no. FKNMS 2002-032. C. Fasano, as well as many volunteers from RSMAS and NOAA, are thanked for their assistance during the fieldwork. Dione Swanson as well as 3 anonymous reviewers are thanked for useful suggestions on earlier drafts of the manuscript. Funding was provided by NOAA Fisheries' Coral Reef Initiative.

\section{LITERATURE CITED}

Babcock RC (1991) Comparative demography of three species of scleractinian corals using age- and size-dependent classifications. Ecol Monogr 61:225-244

Bak RPM, Criens SR (1981) Survival after fragmentation of colonies of Madracis mirabilis, Acropora palmata and A. cervicornis (Scleractinia) and the subsequent impact of a coral disease. Proc 4th Int Coral Reef Symp 2:221-227

Bak RPM, Engel MS (1979) Distribution, abundance and survival of juvenile hermatypic corals (Scleractinia) and the importance of life history strategies in the parent coral community. Mar Biol 54:341-352

Benayahu Y, Loya Y (1984) Substratum preferences and planulae settling of two Red Sea alcyonaceans: Xenia macrospiculata (Gohar) and Parerythropodium fulvum fulvum (Forskal). J Exp Mar Biol Ecol 83:249-261

Berntsson KM, Jonsson PR, Larsson AI, Holdt S (2004) Rejection of unsuitable substrata as a potential driver of aggregated settlement in the barnacle Balanus improvisus. Mar Ecol Prog Ser 275:199-210

Bruckner AW, Bruckner RJ, Williams EH (1997) Spread of a black-band disease epizootic through the coral reef system in St Ann's Bay, Jamaica. Bull Mar Sci 61:919-928

Caley MJ, Carr MH, Hixon MA, Hughes TP, Jones GP, Menge BA (1996) Recruitment and the local dynamics of open marine populations. Annu Rev Ecol Syst 27:477-500

Carlon DB, Olson RR (1993) Larval dispersal distance as an explanation for adult spatial pattern in 2 Caribbean reef corals. J Exp Mar Biol Ecol 173:247-263

Connell JH (1971) On the role of natural enemies in preventing competitive exclusion in some marine animals and in rain forest trees. In: Den Boer PJ, Gradwell G (eds) Dynamics of populations. Center for Agricultural Publication and Documentation, Wageningen, p 298-312

Connell JH (1985) The consequences of variation in initial settlement vs. post-settlement mortality in rocky intertidal communities. J Exp Mar Biol Ecol 93:11-45

Duerden JE (1904) The coral Siderastrea radians and its postlarval development. Publ Carnegie Inst 20:1-130

Dunstan PK, Johnson CR (1998) Spatio-temporal variation in cores recruitment at different scales on Heron Reef, southern Great Barrier Reef. Coral Reefs 17:71-81

Edwards AJ, Clark S (1998) Coral transplantation: a useful management tool or misguided meddling? Mar Pollut Bull $37: 474-487$

Fearon RJ, Cameron AM (1997) Preliminary evidence supporting the ability of hermatypic corals to affect adversely larvae and early settlement stages of hard coral competitors. J Chem Ecol 23:1769-1780

Gotelli NJ (1988) Determinants of recruitment, juvenile growth and spatial distribution of a shallow water gorgonian. Ecology 69:157-166

Harii S, Kayanne H (2003) Larval dispersal, recruitment, and adult distribution of the brooding stony octocoral Heliopora coerulea on Ishigaki Island, southwest Japan. Coral Reefs 22:188-196

Harii S, Kayanne H, Takigawa H, Hayashibara T, Yamamoto M (2002) Larval survivalship, competency periods and settlement of brooding, Heliopora coerulea and Pocillopora damicornis. Mar Biol 141:39-46

Harrigan JF (1972) The planulae of Pocilloporia damicornis: Lunar periodicity of swarming and substratum selection behaviour. PhD thesis, University of Hawaii, Honululu, HI

Hassell MP (1986) Detecting density dependence. Trends Ecol Evol 1:90-93

Heyward AJ, Negri AP (1999) Natural inducers for coral larval metamorphosis. Coral Reefs 18:273-279

Hixon MA, Pacala SW, Sandin SA (2002) Population regulation: historical context and contemporary challenges of open vs. closed systems. Ecology 83:1490-1508

Hughes TP, Jackson JBC (1985) Population dynamics and life histories of foliaceous corals. Ecol Monogr 55:141-166

Hughes TP, Connell JH (1987) Population dynamics based on size or age? A reef coral analysis. Am Nat 129:818-829

Hughes TP, Baird AH, Dinsdale EA, Moltschaniwskyj NA, Pratchett MS, Tanner JE, Willis BL (1999) Patterns in recruitment and abundance of corals along the Great Barrier Reef. Nature 397:59-63

Hunt HL, Scheibling RE (1997) Role of early post-settlement mortality in recruitment of benthic marine invertebrates. Mar Ecol Prog Ser 155:269-301

Hyatt LA, Rosenberg MS, Howard TG, Bole G and 7 others (2003) The distance dependence prediction of the JanzenConnell hypothesis: a meta-analysis. Oikos 103:590-602

Isomura N, Nishihira M (2001) Size variation of planulae and its effect on the lifetime of planulae in three pocilloporid corals. Coral Reefs 20(3):309-315

Janzen DH (1970) Herbivores and the number of tree species in tropical forests. Am Nat 104:501-528

Keough MJ, Downes BJ (1982) Recruitment of marine invertebrates: the role of active larval choices and early mortality. Oecologia 54:348-352

Lasker HR, Kim K (1996) Larval development and settlement behavior of the gorgonian coral Plexaura kuna (Lasker, Kim and Coffroth). J Exp Mar Biol Ecol 207:161-175

Lewis JB (1974) The settlement behaviour of planulae larvae of the hermatypic coral Favia fragum (Esper). J Exp Mar Biol Ecol 15:165-172

Lewis JB (1989) Spherical growth in the Caribbean coral Siderastrea radians (Pallas) and its survival in disturbed habitats. Coral Reefs 7:161-167

Lindahl U (2003) Coral reef rehabilitation through transplantation of staghorn corals: effects of artificial stabilization and mechanical damages. Coral Reefs 22:217-228

Lindquist N (1996) Palatability of invertebrate larvae to corals and sea anemones. Mar Biol 126:745-755

Lindquist N, Hay ME (1996) Palatability and chemical defense of marine invertebrate larvae. Ecol Monogr 66:431-450

Lirman D, Manzello D, Macia S (2002) Back from the dead: the resilience of Siderastrea radians to severe stress. Coral Reefs 21:291-292

Menge BA (19919 Relative importance of recruitment and other causes of variation on rocky intertidal community structure. J Exp Mar Biol Ecol 146:69-100 
Miller K, Mundy C (2003) Rapid settlement in broadcast spawning corals: implications for larval dispersal. Coral reefs 22:99-106

Morse DE, Hooker N, Morse ANC, Jensen RA (1988) Control of larval metamorphosis and recruitment in sympatric agariciid corals. J Exp Mar Biol Ecol 116:193-217

Moses CS, Swart PK, Helmle KP, Dodge RE, Merino SE (2003) Pavements of Siderastrea radians on Cape Verde reefs. Coral Reefs 22:506-506

Mundy CN, Babcock RC (1998) Role of light intensity and spectral quality in coral settlement: implications for depthdependent settlement? J Exp Mar Biol Ecol 223:235-255

Mundy CN, Babcock RC (2000) Are vertical distribution patterns of scleractinian corals maintained by pre- or postsettlement processes? A case study of three contrasting species. Mar Ecol Prog Ser 198:109-119

Neves EG, da Silveira FL (2003) Release of planula larvae, settlement and development of Siderastrea stellata Verrill, 1868 (Anthozoa, Scleractinia). Hydrobiologia 501:139-147

Nonaka M, Baird AH, Kamiki T, Yamamoto HH (2003) Reseeding the reefs of Okinawa with the larvae of captivebred corals. Coral Reefs 22:34

Olson RR (1985) The consequences of short-distance larval dispersal in a sessile marine invertebrate. Ecology 66: 30-39

Polacheck T, Stimson J (1994) Experimental investigations into the basis of the uniform dispersion pattern of Pocillopora meandrina dana var nobilis Verrill, 1864. J Exp Mar Biol Ecol 181:189-199

Rannar S, Lindgren F, Geladi P, Wold S (1994) A PLS kernel algorithm for data sets with many variables and fewer objects. Part 1. Theory and algorithm. J Chemometrics 8: 111-125

Rinkevich B (1995) Restoration strategies for coral reefs damaged by recreational activities: The use of sexual and asexual recruits. Rest Ecol 3:241-251

Roughgarden J, Iwasa Y, Baxter C (1985) Demographic theory for an open marine population with space-limited recruitment. Ecology 66(1):54-67

Sakai K (1997) Gametogenesis, spawning, and planula brooding by the reef coral Goniastrea aspera (Scleractinia) in Okinawa, Japan. Mar Ecol Prog Ser 151:67-72

Sammarco PW, Andrews JC (1988) Localized dispersal and

Editorial responsibility: Charles Birkeland (Contributing

Editor), Honolulu, Hawaii, USA recruitment in GBR corals: the helix experiments. Science 239:1422-1424

Smith JE, Smith CM, Hunter CL (2001) An experimental analysis of the effects of herbivory and nutrient enrichment on benthic community dynamics on a Hawaiian reef. Coral Reefs 19:332-342

Smith LD, Hughes TP (1999) An experimental assessment of survival, re-attachment and fecundity of coral fragments. J Exp Mar Biol Ecol 235:147-164

Soong K (1991) Sexual reproductive patterns of shallowwater reef corals in Panama. Bull Mar Sci 49:832-846

Steen H, Scrosati R (2004) Intraspecific competition in Fucus serratus and F. evanescens (Phaeophyceae: Fucales) germlings: effects of settlement density, nutrient concentration, and temperature. Mar Biol 144:60-77

Steneck RS, Dethier MN (1994) A functional-group approach to the structure of algal-dominated communities. Oikos 69:476-498

Steneck RS, Testa V (1997) Are calcareous algae important to reefs today or in the past? Symposium summary. Proc 8th Int Coral Reef Symp 1:685-688

Underwood AJ, Denley EJ (1984) Paradigms, explanations and generalizations in models for the structure of intertidal communities on rocky shores. In: Strong DR, Simberloff D, Abele LG, Thistle AB (eds) Ecological communities: conceptual issues and the evidence. Princeton University Press, Princeton, NJ, p 151-180

Uriz MJ, Maldonado M, Turon X, Marti R (1998) How do reproductive output, larval behaviour and recruitment contribute to adult spatial patterns in Mediterranean encrusting sponges? Mar Ecol Prog Ser 167:137-148

Van Moorsel GWNM (1983) Reproductive strategies in two closely related stony corals (Agaricia, Scleractinia). Mar Ecol Prog Ser 13:273-283

Wethey DS (1986) Ranking of settlement cues by barnacle larvae: influence of surface contour. Bull Mar Sci 39:393-400

Young CM (1988) Direct observations of field swimming behavior in larvae of the colonial ascidian Ecteinascidia turbinata. Bull Mar Sci 39:279-289

Young CM, Chia FS (1984) Microhabitat-associated variability in survival and growth of subtidal solitary ascidians during the first twenty-one days after settlement. Mar Biol 81:61-81

Submitted: May 27, 2004; Accepted: February 22, 2005

Proofs received from author(s): May 13, 2005 